Human Ethology Bulletin 31 (2016)4: 15-33

Theoretical Review

\title{
MENTALISTIC AND SCIENTIFIC STORIES ABOUT HUMAN BEHAVIOR, BIOMIMETIC HEURISTICS AND PSYCHOLOGY'S CONFUSIONS
}

\author{
John Richer \\ Paediatric Psychology, Oxford University Hospitals, Oxford UK \\ Department of Physiology, Anatomy and Genetics, University of Oxford \\ johnricher@oxhs.co.uk
}

\section{WHAT THIS PAPER IS ABOUT}

This paper is about a number of connected issues:

- Mentalism and why and how we are a mentalistic species.

- Why there are two, equally important, stories about human behaviour, the mentalistic and scientific, whose differences need to be clearly understood.

- Why the mentalistic story of human behaviour is flawed starting place for a scientific study of ourselves, though absolutely necessary for everyday life. That necessity and utility has seduced many psychologists erroneously to start their would-be science with mentalistic concepts.

- And yet, in the manner of those practicing biomimetics, how scientists can learn from evolved mentalism, and in particular the pervasiveness of the mentalistic understanding people at the level of motivations (feelings, intentions, etc.), and work on the heuristic expectation that patterns in behaviour will be found, not at the behavioural level, but at the level of motivation albeit inferred from the observed behaviour.

Keywords: Ethology, motivational analysis, biomimetics, mentalism, direct observation, psychology's shortcomings. 


\section{ABSTRACT AND PREAMBLE}

Biomimetics is an approach where technological problems are informed by the evolved solutions to similar problems "in nature". Learning about optimal marine design from studying fish and marine mammals is one example. Another is the invention of Velcro by Georges de Mestral after he observed how burs (burrs) stick to fur and clothing. An example closer to Ethology is "neuromorphics" in which computer scientists draw on the functioning of nerve cells to create more efficient and powerful computer systems (e.g. Mead, 1990; Tuma et al, 2016).

Whilst ethology is a science, not a technology, the biomimetic approach has relevance to its methodology, which can be seen as the technological aspect of the science. More specifically scientists studying human behaviour can ask how, over human evolution, people have solved the everyday problems of understanding and dealing with each other, even though their approach has not been a scientific one.

To anticipate, I shall argue that, as a mentalistic / intersubjective species, we view each other in terms of inferred feelings, thoughts and intentions, and do not, by and large, make detailed inventories of people's observable behaviour, although we clearly react to subtle differences in such behaviour. Thus we have evolved an approach which implies that the most efficient way of understanding and dealing with others is to infer thoughts and motivations, and their input side corollary, emotions. This suggests that patterns in behaviour will be most usefully discerned at the level of motivations rather than overt behaviour.

Many psychologists and other social scientists have simply taken the ordinary emotion and motivation terms of their culture / language and used this as the starting point. As reasonable as this sounds, it has resulted in a failure adequately directly to observe naturally occurring human behaviour and describe it in publically observable terms, the usual starting point of any science. The upshot is that the "science" is more about the cultural terms than the real behaviour. Moreover these terms often embrace the subjective, the first person perspective, which is essential for a mentalistic species, but has no place in science. The conclusion from this is that whilst the terms of everyday ordinary language which describe thoughts, feelings and intentions are an inadequate starting point in a science of human behaviour, and painstaking direct observation of naturally occurring behaviour is necessary, patterns in behaviour are likely to be found at the level of motivations inferred from this observation.

\section{NEGATIVES AND POSITIVES OF USING ORDINARY LANGUAGE TERMS}

Early attempts to create a human ethogram produced long lists of well described observable behaviours, which often yielded valuable insights, (e.g. Grant, 1969; McGrew, 1970; Blurton Jones, 1972; Richer, 1976, 1979) but were not widely taken up as a basis for understanding human behaviour. Most research continued with the traditional methods of 
psychology: these included, for example, questionnaires and rating scales, or recordings of behaviour, gathered because a psychological concept is operationally defined by them. All of these approaches measured psychological concepts which were derived, mainly, from the everyday ideas about emotion, cognition and the like. Examples include measures of emotions such as anger, fear, anxiety, sadness, or personality differences, or preferences relating to, say, attractiveness. Even when an evolutionary approach was applied, as in the discipline of Evolutionary Psychology, the same data collection methods were often employed as had been used in mainstream psychology for decades. Most of the concepts measured have the benefit of familiarity and utility, since they are so helpful in everyday social life, at least to those in the culture from which they are drawn. This approach had negative and positive scientific aspects, which get to the heart of the conceptual difficulties in studying our own species.

\section{Negative aspect 1 - what are the natural phenomena?}

The first negative aspect has long been recognised. Tinbergen (1963) memorably wrote, "It has been said that, in its haste to step into the twentieth century and to become a respectable science, Psychology skipped the preliminary descriptive stage other natural sciences had gone through, and was soon losing touch with the natural phenomena". Ethology traditionally, and appropriately, demanded observation of the natural phenomena (i.e. phenomena uninfluenced or minimally influenced by the scientist, (Richer, 1974)). That provided a starting point of what needs to be understood. Without it, the would-be scientists do not know, literally, what they are talking about. Much psychology skipped this preliminary observation and adopted the so called "hypothetico-deductive" method (e.g. Godfrey-Smith, 2003 p. 236, Haig, 2009), which emphasises the need to start with a hypothesis which is then tested. This method might be seen a welcome advance on mere assertion of a belief, but that sets the bar pretty low for judging an approach as scientific. It has been criticised in many ways, but crucially the question that is often not asked is, "from where does the hypothesis come, from what observable natural behaviour does it arise and what naturally occurring behaviour is it intended to help explain?. The answer is rarely forthcoming and this is where the approach falls down - the research is not about the real publically observable world, but about ideas derived from whatever is the psychologist's culture. Blurton Jones (1975) put this very succinctly when he said "the lateral thinking inductive approach of ethology may be contrasted with the deductive approach of psychology and its disdain for facts for their own sake" (page 72). Charlesworth (pers. comm.) puts it even more succinctly, if slightly cryptically: "follow the duck, not the theory of the duck".

Some psychologists try to rectify this, and connect with observable behaviour, by operationally defining their measures, i.e. by defining what they mean by, for example, "angry" by describing a set of observable behaviours. But this still begs the question of why they are bothering to measure this thing (e.g. "anger") at all. The cart is put before the horse, the concept is decided and then operationally defined. As Blurton Jones says, it is a 
deductive, not an inductive, process. What often happens when these operationally defined concepts are used is that the discussion slips back to talking about the ordinary meaning of the concept measured. The result is a mess of (usually) precise data, but loosely and imprecisely connected to the natural phenomena and where the illusion of relevance is created by the familiarity of the concept being measured and its usefulness in everyday life.

Yet, it may be replied, these ideas are extremely useful in the psychologists' cultures. They help everyday communication and since they are widely understood, they must have some clear connection to real behaviour and must thus be a good starting point for a scientific enquiry. But this is to misunderstand the function of these everyday concepts. Just because they are useful within a culture is no guarantee that they will useful in a scientific understanding of that culture. A similar point was made some 50 years ago by linguist and anthropologist Kenneth Pike (Pike, 1967), when he distinguished between emic descriptions of a culture which use the culture's own terms and etic descriptions which use the observer's term. In science, descriptions inevitably use etic terms, because the phenomena studied (e.g. atoms, molecules, plants, animals) have no terms of their own. Only the social sciences have the problem where their subject matter, humans, uses terms relevant to a description of their own behaviour. Social scientists have been seduced into using such emic terms as part of their "scientific" (etic) vocabulary.

A similar distinction to Pike's was made by Harre and Secord (1972) describing the two aspects to the study of human social behaviour:

1. "Negotiation of accounts"

2. "Micro sociological analysis"

The first, the "negotiation of accounts", involves discussion with the people being studied, trying, through a process of to and fro conversation, to understand as well as possible what their viewpoints were. Inevitably this process involves using the (emic) concepts of the people involved, otherwise there would be no communication.

The second, what they call the "micro sociological analysis", involves observing behaviour, as an ethologist would observe the behaviour of non human species, using the observer's own (etic) categories to describe the behaviour under investigation.

\section{Negative aspect 2 - first person perspectives and subjectivity.}

The British Psychological Society defines psychology as the "Science of Mind and Behaviour". This embraces the subjective (the mind) as well as the objective (the behaviour). Emic mental state terms are inevitably used by psychologists since this is the subject matter of, at least, part of the research (the Mind part).

Mental states terms refer both to states in oneself and states of others. So we can say (i) I feel happy, and (ii) you feel happy / he or she feels happy. As Wittgenstein (1953) pointed out, mental state words must be sufficiently "defined" (implicitly) in terms of publically observable behaviour and situations if we are all to use them in much the same way, i.e. if they are to have any clear shared meaning. But on the other hand, each of us uses them to 
describe his own experience and his own actions, and my intention when using them about others is to refer to their subjective state as well as their behaviour. Single words contain both these viewpoints. I shall call these two viewpoints that of the agent (who refers to themselves as "I") and of the onlooker (who talks about "you, he or she")

The study of subjective experience has been firmly rejected as not possible, or as not useful, as part of a scientific approach by many, for instance Watson (1913) or Tinbergen (1951) and is rejected here (see also Richer, 1975).

To understand further why the subjective knowledge cannot be an object of scientific study in the way some psychology tends to, it is important to look not at knowledge but at agreements.

\section{Types of agreement}

Any corpus of shared knowledge consists of agreements between individuals. If there are no agreements there is no shared knowledge. Private knowledge does not require that sharing, but then it cannot be part of the shared body of knowledge, and so is not something, a priori, that we can talk about and be understood. Just as fish are, as the saying goes, the last to discover water, this simple point has a significance which seems to elude many.

I must make a clarificatory addition to this. Much of human progress has been brought about by individuals making public their own novel ideas (see for instance, Henshilwood and Dubreuil $(2009,2011)$ ). The private become public. But this process, often fraught and tortuous, is one where the individual and others in the end come to agree on shared meanings of the terms used. The idea gets into the public, shared, domain.

So, in this discussion, we must give intellectual priority to agreements, which can only be public, and not focus on knowledge, which can be both public and private.

Two types of agreements may be distinguished: Negotiated ( $\mathrm{N}$ type) and Demonstrated (D type) (Richer, 1975). An example of Negotiated agreements is: we agree that this colour means "red", or that "flower" means this sort of thing and we agree on the use of "this" and "is". What words (in the sense of the sounds we make or the marks on paper) are used is largely arbitrary, (and different in different languages) and the exact boundaries of the meanings are sometimes fuzzy and/or different in different languages (Nagel, 2014).

Possessing these Negotiated agreements enables us to proceed to Demonstrated agreements. A Demonstrated agreement is of the type, for example, "this flower is red". Having agreed the meanings of each word we can agree, or disagree, on "this flower is red" simply by demonstration, perhaps by pointing at it.

Negotiated agreements can be changed and are judged by whether they are useful, demonstrated agreements are judged by whether they describe the real shared world accurately, by whether they are, in this sense, true.

\begin{tabular}{lll}
\hline Type of agreement & Evaluated according to \\
\hline $\mathrm{N}$ & Negotiated & Usefulness \\
$\mathrm{D}$ & Demonstrated & Truth \\
\hline
\end{tabular}


Thinkers have become sidetracked into asking questions about subjective knowledge, and easily come to confuse private knowledge, which cannot be discussed until it is shared, with shared knowledge.

\section{Agreements in Science}

In science this agreement process is formalised and tightened: terms are carefully and precisely defined, or at least the attempt is made to do so, and the phenomena under study are described in these terms. A hypothesis couched in these terms can be tested by an attempt at demonstration, such that, having accepted the terms, the scientists can agree after a demonstration on what the result is. Science, as Medawar (1967) argued, is about creating a coherent story about the facts and which can be tested by seeing whether it accords with the facts. The facts are the demonstrated agreements.

The actual conduct of science is not so neat as this. Methodology and terminology are disputed. There can be debate, (negotiation), about the meanings of terms. This is often not a dispassionate process, a lot of politics and persuasion enters into it. The persuasive powerful professor will often get his definition agreed even though many may privately hold the view that it is less useful than its competitors. Lehrman (1970) argued that disputes in science are usually about the terms used and rarely about the facts.

\section{Why "the Science of Mind and Behaviour" is an oxymoron}

The foregoing discussion has raised the question of whether the definition of psychology by the British Psychological Society as the "Science of Mind and Behaviour", is an oxymoron, i.e. because mental states cannot be studied by the accepted methods of science.

The short argument is that the meaning of everyday mental state terms involves both the subjective and objective, both the agent's perspective ("I") and the onlooker's perspective ("you, he, she"). The agent's perspective cannot be agreed by demonstration - it is available to only one person - and so cannot constitute a body of facts on which a science can be based and hypotheses tested.

\section{Two types of story about human behaviour}

The longer argument involves seeing that there are two distinct types of story about human behaviour. One type involves the agent's perspective and is the story we are familiar with, it being integral to our cultures. The other type involves only the onlooker's perspective and its clearest exemplar is science. The differences between these two approaches, onlooker and agent, are summarised in table 1.

Darwin himself painfully experienced this when his much loved daughter Annie died at the age of 10 (Keynes, 2001). He wrote "We have lost the joy of the household, and the solace of our old age.... Oh that she could now know how deeply, how tenderly we do still \& and shall ever love her dear joyous face." (Browne, 1995, p. 501). Viewed from the onlooker 
stance, here was natural selection in operation, but viewed from the inside there was only anguish and grief.

Table 1. Two approaches to the study of human behavior

\begin{tabular}{ll}
\hline Agent & Onlooker \\
\hline Sharing Minds & Observing Bodies \\
Agency involved, action & Onlooking only, events \\
I do & He/she/it does, or, It happens \\
Feelings, intentions, reasons & Causes, effects, goals \\
Free will & Determinism \\
Emic (culture's own terms) & Etic (observer's terms) \\
Useful for communication in a culture & For communication about a culture \\
Arts, Religions & Sciences \\
Persuasion & Manipulation \\
Symptoms & Signs \\
Content of consciousness & Phenomenon of intersubjectivity \\
Demonstrated agreements not required & Demonstrated agreements required \\
\hline
\end{tabular}

For the avoidance of doubt, I am not saying one approach is "superior" to another, they are simply different and have different functions, one examines human behaviour from an onlooker stance in the same way as the behaviour of any other species would be researched. Science tells this story. In the other approach, we study our fellow humans as agents with a subjective life that can be shared. This is the approach of artists, poets, novelists, philosophers, musicians, clerics, etc.. This second approach is essential, it gives our lives meaning, colour, beauty, direction and connection with others. It has evolved and had great adaptive value. It is what we do naturally.

The difference is made clearer by MacKay's (1960) powerful argument of the relationship between, and compatibility of, Determinism and Free Will. He asks the reader to imagine a person in a room (Figure 1), I shall call them the Agent, who has to make decisions about what to do next. He is observed by an Onlooker, who, it is supposed, has complete knowledge about this person such that he can predict what the Agent will do. From the Onlooker's point of view the Agent's behaviour is determined. From the Agent's point of view he does not know what he will do until he has decided. From his point of view he has Free Will. So at one and the same time the Onlooker can be able to predict deterministically what the Agent will do, and the Agent will, from his point of view, have Free Will. MacKay describes this as "psychological relativity". He adds a rider; if the Onlooker tells the Agent what his prediction is, that automatically invalidates the prediction. Why? Because the prediction becomes a factor the Agent takes into account in making his decision, and the prediction cannot a priori take that into account. That is a version of Gödel's theorem - no system can totally explain itself. A key difference between the two 
positions is whether the content of the first person perspective, the Agent's conscious experience, is part of the picture, for the Onlooker it is not, for the Agent, a priori, it is. In most human social life, we deal each other as Agents who have Free Will.

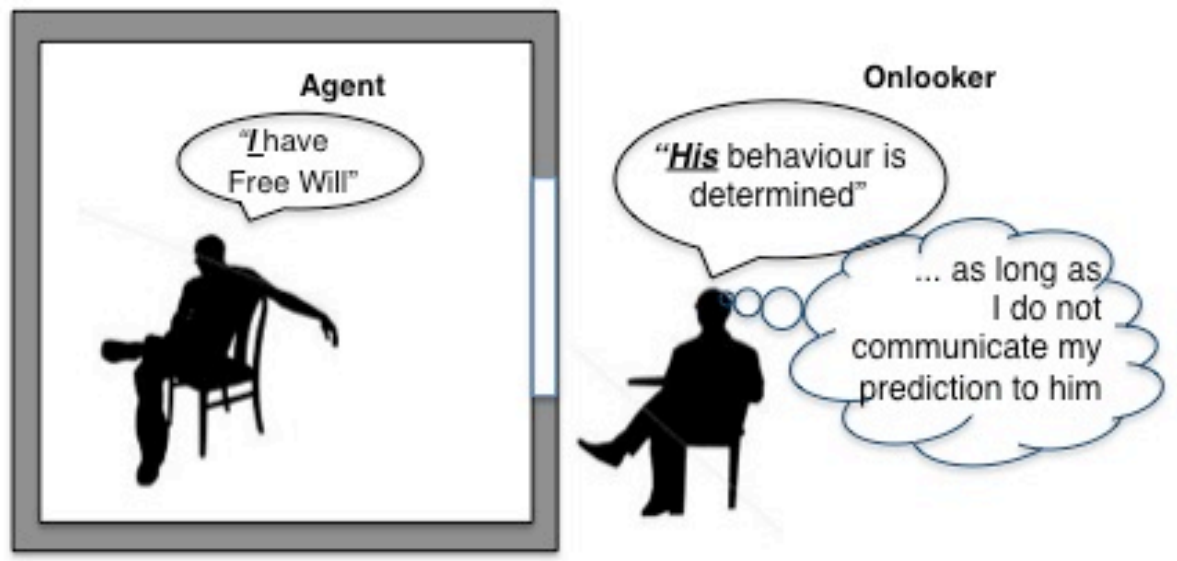

Figure 1 Illustration of MacKay's (1960) argument for the compatibility of Free Will and Determinism.

The juxtaposition of these two stories was nicely illustrated in the film Ex Machina (Garland 2015). A young programmer, Caleb, is flown to the mountain retreat cum laboratory of Nathan, the immensely wealthy owner of a huge IT company, who seeks to build humanlike robots. He sets Caleb a kind of Turing test: at the end of a week, will Caleb treat a robot, Ava, as a conscious being with feelings? The difference from the usual Turing test is that Caleb knows the robot is not human. Still, Ava passes the test. The conceptual sophistication of this film is this. We humans know we are machines, albeit biological, not electronic. Yet we still treat each others as conscious beings. We simultaneously embrace the stories of both onlooker and agent.

\section{Positive aspect: the implication of mentalism for understanding at the level of motives}

We are a mentalistic / intersubjective ${ }^{1}$ species, we see each other in terms of our feelings, intentions, and the like. We do not usually see each other only in terms of eye brow raising, mouth corner position, etc. indeed most people are hard put to describe such behaviour even though they are clearly reacting to subtleties of another person's behaviour (Trevarthen and Aitken, 2001; 2003; Frith and Frith, 2003; Fonagy et al, 2004, 2011). The agent's story is the one which we use with ease. Before looking at the positive aspect of this, I

\footnotetext{
${ }^{1}$ the term "intersubjectivity" (Trevarthen, 1980) is useful since it emphasises the sharing between individuals (inter) of subjective experience.
} 
shall discuss the nature, evolution, ontogeny and adaptive value of mentalism / intersubjectivity.

\section{The Ethology of Mentalism}

The phenomena of mentalism / intersubjectivity include:

- that humans usually deal with each other as beings with a first person perspective;

- they ascribe Agency, Free Will and Consciousness to each other;

- they empathise and are capable of seeing the perspective of others (first order Theory of Mind) and sometimes can see the view someone has of third person's perspective (second order Theory of Mind); and so on to further orders of Theory of Mind

- they develop systems of shared meaning - their cultures;

- all cultures studied have words for "I" and "you", although, interestingly, not all have the third person terms (Nagel, 2014);

- mental state words contain the first person perspective, as well as second and usually third person perspectives (I am angry. You are, he/she is, angry)

- people are able to deceive in novel ways and see through attempted deception.

I shall look at this phenomenon using three of Tinbergen's four Whys. I shall not explore here Tinbergen's first "Why" which would concern the proximate causes of Mentalism. If I were to I could perhaps look at situations and states where individuals are more or less mentalistic. Some of the most obvious are that the ability to be mentalistic often reduces with stress, or with the cultural distance between two individuals, but given that mentalism is an underlying and pervasive ability, such assertions stand in need of much unpicking and support, and that would distract from the main argument of this piece.

\section{Evolution of mentalism / intersubjectivity}

The ability to imitate has a key role in the evolution of mentalism. In imitation the neural input from observing a conspecific doing something is translated into very different output to produce the "same" behaviour (Hinde, 1953). Being able to make this translation is a necessary ability if one individual is to begin to see the behaviour of another in terms which include what he $\mathrm{e}^{2}$, himself, would be intending if behaving like this, thus he can recruit the enormous "processing power" controlling his own behaviour for seeing the intentions of others. Essentially, the question asked is, "if I were doing that, what would I be intending?" Humphrey (1976) notes that part of this ability to see the intentions of others is an assumption that conspecifics are roughly similar to oneself and so one can inform one's ideas about the other individual's feelings and intentions by using knowledge of what one would intend or feel in a situation when behaving in a similar way. This assumption is likely to be more useful when the individuals belong to the same group.

\footnotetext{
${ }^{2}$ For the sake of brevity only, the masculine pronoun is used.
} 
More recent research into the mirror neuron system (MNS), which is the neural substrate of part of the translation mechanism, has generated similar ideas. Gallese et al (2004) and Colle et al (2008) discuss the translation, via the MNS, of "visual information about physical movement into knowledge about an intentional action" (Colle et al 2008, page 338). Buccino et al (2004) used fMRI techniques to look at the extent to which, the MNS was activated by observing some actions of non conspecifics (monkey and dog). They found that the MNS was activated when the human subjects were observing biting whether done by a human, monkey or dog. But when "oral communicative actions" (human silent speech, monkey lip smacking and dog barking) were presented, they found that MNS areas were activated when observing actions that were part of the repetoire of the observer (silent speech, and to a lesser extent, lip smacking), whereas they were not when observing one that was not part of that human repetoire (barking). They concluded, "when the motor representation of the observed action is activated, the observer gains knowledge of the observed action in a "personal" perspective, while this perspective is lacking when there is no motor activation". Seeing becomes doing and experiencing.

The evolution of mentalism / intersubjectivity has been discussed by many authors. The "Machiavellian Intelligence" hypothesis (Bryne \& Whiten,1988) argues that, in some group living primate species, a selective advantage in the competition between group members for resources (food, mates, etc.) was obtained when an individual could deceive another to its own advantage and could see through the deceptions of others to avoid being exploited. An "arms race" for better deception and better detection ensued. (Humphrey, 1976, 1982; Dawkins \& Krebs, 1978; Krebs \& Dawkins 1984; Whiten \& Byrne, 1988, 1997). Having the ability to imitate was a necessary, though not sufficient, condition for this to occur. This arms race was argued to help drive a growth in brain size (Humphrey, 1976). Dunbar, (1995) argued that larger brain size was necessary for storing the huge amount of information about the behaviour of conspecifics and the multiple relationships in large groups.

This "Machiavellian Intelligence" argument emphasised competitive advantages. The "Cultural Intelligence" hypothesis (Whiten and van Shaik, 2007; Boyd \& Richerson, 1996; Tomasello et al, 2005) emphasised the selective advantages of cooperation. Mentalising abilities greatly aid cooperation in part by aligning intentions and understandings. Effective communication and cooperation within one's own group is argued to confer advantage on the group and so on its members and, in turn, to be a pressure for further improvement of mentalism (Cortini \& Liotti, 2010). The tendency to punish cheats and free loaders, even at some expense to the punisher, is part of the evolved mechanism for maintaining cooperation (Richerson et al 2003; dos Santos et al, 2011). Knight (1998), Noble (2000) and others argue the necessity of cooperative relationships for the evolution of language. Henshilwood (2012) and Henshilwood and Dubreuil $(2009,2011)$ describe the long periods in human evolution of living in small extended family groups, which would have provided a necessary condition for sophisticated cooperation, including symbol development, having a selective 
advantage. They also argue for the importance of the ability to take the perspective of the other (facilitated by the translation mechanism in imitation).

This ability to be intersubjective / mentalistic and intentionally send meaningful messages is shared with some other large brained social species (McGrew, 2005; Whiten \& van Schaik, 2007, Hobaiter \& Byrne, 2014; Clay et al, 2015). But it seems that it is only in humans that "cumulative culture" has evolved where more sophisticated traditions are built upon previous ones (Whiten \& van Schaik, 2007; Dubreuil and Henshilwood, 2013). The evolution of language and other symbol systems then allowed these shared understandings to exist independently of individual relationships and to be the accumulating property of the whole group.

As is well known, some have argued that this cultural space has become an environment in which the basic units of shared information - variously called "memes", culturgens", "concepts" or "cultural traits" (Dawkins, 1976; Lumsden \& Wilson, 1980; Mayr, 1997; Lyman and O'Brien, 2003) - compete and are selected for, or not, just as genes are selected for in the biological environment.

This shared culture and the human proclivity to cooperate and be intersubjective, as well as to compete, has led some to argue that human groups function in some ways like superorganisms, akin to the social insects (e.g. Kesebir 2012). The idea is an old one, dating back at least to Herbert Spencer (1891), and taken up in different forms by many since (e.g. Richerson \& Boyd, 1999; Haidt 2012; Wilson, 2012). John Donne in 1623 was alluding to the same idea in his Meditation 17 ('no man is an island...') (Donne, 1923). It has been argued that groups which were able to cooperate better and maximise altruism within the group generally were more successful in a Darwinian sense (Richerson et al, 2003). The internet, like all advances in communication technology before it (writing, printing etc.), has progressively expanded the potential size of this superorganism with its shared consciousness.

\section{Ontogeny}

Most children start life with strong motivations to be sociable, plus the ability to imitate is soon manifest ${ }^{3}$, and over the first 18 months, through intensive interaction with their caregivers, develop the beginnings of mentalising abilities such that others are treated as agents with free will and with their own perspective and conscious experience, and where skills for fluent social interaction and use of language and other symbols begin to be refined. The child negotiates shared meanings (Newson \& Newson,1975) and is drawn into the shared mind which is their culture. In particular, they negotiate the meanings of words describing mental states.

\footnotetext{
${ }^{3}$ I leave aside the question of whether this ability is present at birth (Meltzoff and Moore, 1977)) or soon present as a result of differential social reinforcement (Ray and Heyes 2011).
} 
The development in childhood of intersubjectivity / mentalising abilities has been extensively described by a number of authors (e.g. Trevarthen \& Aitken, 2003; Frith \& Frith, 2003; Fonagy et al, 2004, 2011), so only one illustration will be given here.

From birth to about 2 to 4 months, is the stage of what Trevarthen $(1977,1980)$ calls "primary intersubjectivity". It is characterised by face to face, to and fro "conversations" between mother and infant, involving smiling, gaze fixating, vocalisating, imitating and making a range of other movements towards each other. It is seen as the first stage of a sharing of minds, of the baby developing the idea that the mother knows what they are feeling and thinking (not consciously, of course). Of vital importance is the sensitivity of the mother to the infant's state of mind and a key feature of that is contingency, the mother reacts to what the infant has just done (and vice versa).

In a classic experiment, Murray and Trevarthen (Murray, 1980; Murray and Trevarthen, 1985), connected mother and her 2 month old infant via closed circuit television, so the infant saw mother on screen and the mother saw the infant. Quite soon most started "chatting" normally via this link. There were two conditions where this conversation was disrupted. In one condition the mother was asked to stop responding and maintain a still face, in the other a video recording of the mother conversing with her infant was played to the infant. In both conditions the infant first tried to maintain the interaction but then quickly gave up and looked depressed. In both situations the contingency of the mother's behaviour with the infant's was disrupted, and the infant's reaction showed that they expected such contingency, and that not getting it was aversive. So from very early in life, infants have an expectation of (proto) agreement about mental states. Murray and Trevarthen (1986) also showed that when mothers were played a recording of their infants (the second disrupted condition but reversed), their behaviour differed significantly from the ordinary contingent conversation and they very quickly recognised they were not being attended to and "talked" with. In other words both mother and baby have strong expectations of contingent interaction. It is in these interactions that the sharing of minds and drawing the child into their culture begin.

There are some natural experiments illustrating this. For instance, some of the children later diagnosed autistic, were described by their parents, in early studies, as "happiest when left alone" and later studies looking at home videos, showed rather passive, non initiating, non reactive babies (Massie 1978a,b). These children come to have difficulty being fluently mentalistic (see next section).

\section{Adaptive value}

Poor mentalising abilities are associated with several states of reduced adaptiveness. Fonagy et al $(2004,2011)$ have discussed the poor mentalising abilities in some people with psychiatric diagnoses, particularly Borderline Personality Disorder.

The extreme case of deficient mentalising skills is in children diagnosed with autistic spectrum disorders. Children with autistic behaviour tend strongly to avoid the communicative social interactions in which the skills and understandings of the culture are, 
in large part, negotiated and acquired. Thus they are delayed in their acquisition of the skills of their culture, especially those skills predominantly acquired in interaction with others (Richer 1978, 2001a+b). They have difficulty integrating the viewpoints of agent and onlooker ("I" vs "you/he/she"), which most children achieve with ease (Richer, 2001b). Donna Williams was diagnosed autistic when a child but improved considerably and has written and lectured about her experiences. In her book "Autism - an inside out approach", she refers to this same integration problem. She writes:

'I learned to act as though I had a sense of 'us' and 'we' even if my systems integration problems made it very difficult to consistently process internal 'self and external 'other' at the same time; an experience that is essential to grasping what 'social' is, and how to be it and why you might want to be." (Williams, 1996, page 5)

Autistic children are said to have a deficient "theory of Mind", to be "Mindblind" (Frith 1989, Baron-Cohen, 1995), such that they cannot properly empathise and see the point of view of others. In fact, such "deficits" are neither confined to autism nor necessary for it (Richer, 2001b), but the prevalence of such difficulties in children with this diagnosis points to the importance of integrating the perspectives of Self (I) and Other (you/he/she) as part of becoming a fully paid up member of a culture. When this is severe, people have great difficulty knowing what a child with autism is thinking and feeling.

\section{BIOMIMETICS}

We have evolved into a species which is mentalistic / intersubjective. This ability develops in the early years of life as each child learns the skills of the culture, and this has clear adaptive value for individuals.

Given that being mentalistic has great adaptive value, what can we infer from this to help our discipline of human behaviour research? This is the approach of biomimetics, sometimes called Bioinspiration, where technological problems are informed by the evolved solutions to similar problems "in nature". Learning about optimal marine design from studying fish and marine mammals is one example. Another is the invention of Velcro by Georges de Mestral after he observed how burs (burrs) stuck to fur and clothing. An example closer to ethology is "neuromorphics" in which computer scientists draw on the functioning of nerve cells to create more efficient and powerful computer systems (e.g. Mead, 1990; Tuma et al, 2016).

So if the mentalistic approach is so successful, why should a scientific study of human behaviour not use this approach - as traditional psychology often does? The answer why not is given in the foregoing sections. Essentially, the use of mentalistic concepts from the culture had lessened the felt need to find out and clearly describe what the observable behaviour of our own species was, and in any case we felt very familiar with that behaviour albeit without having a basic objective description, and we jumped to the higher order mentalistic concepts so useful in everyday (non scientific) life. A further problem is that 
reference to subjective experience is wrapped up in these concepts, and such experience cannot be the subject of scientific study.

But there is one lesson to be learnt from biomimetics and it is this. Mentalistic approaches generally use concepts at the level of motives, intentions, and, their corollary on the input side, feelings and emotions. This is not at the level of observable behaviour. It is at the level which best and most efficiently enables people to coordinate action and maintain relationships when cooperating, and to deceive or see through deceit in competitive relationships. These were the benefits which were argued to have driven the evolution of mentalism. So it is likely that patterns in behaviour will most easily emerge from analysis at this level.

In ethology, the procedure of inferring common motivation by observing co-occurrence, common consequences and common causes is well established (Baerends, 1941; Tinbergen, 1951). In species less complex and flexible than humans, this is perhaps easier. Even with these, but particularly with humans, underlying motivations may be manifest by different observable behaviours. For example, fear driven behaviour may show itself is outright flight, but also in gaze aversion or certain facial expressions (Richer, 1976). Also the overt behaviour is very often a product of the arousal of more than one motivational system producing motivational conflict; one example is displacement activities, and there is a large variety of such activities of varying complexity seen in humans (Richer, 1979).

But given the success of mentalism, it is likely that this will be a fruitful approach in humans and more likely to yield regularities and understandable patterns of cause and effect, compared to simply focussing on the observable behaviour elements only.

The value of this approach has already been seen. A well known example is attachment theory (e.g. Bowlby, 1969; Cassidy and Shaver, 2008, Crittenden, 2008). Another comes from looking at the motivations underlying autistic behaviour or anorexic behaviour (e.g. Richer, 1976, 2014a,b).

But it needs to be emphasised that the initial observation of behaviour has to be done, (and has not adequately been done by psychology) to infer motivational structures. But, after that, predictions are likely to be most fruitfully generated at the motivational level.

So the methodological lesson is:

- observe a wide range of naturally occurring behaviour,

- infer underlying motivations,

- look for patterns of cause and effect in the functioning of motivational systems

- refine understanding of the motivational systems and their causes, ontogeny, adaptive value and evolution

This is classic ethology, and although analysis at a motivational level is not novel, the emphasis on its likely heuristic value and why, and the necessity of avoiding the errors of psychology as a would-be science and why, is what I have discussed in this paper. 


\section{REFERENCES}

Baerends, G.P. (1941) Fortpfanzungsverhalten und Orientierung der Grabwespe Ammophilia campestris Jur. Tijdschrift voor Entomologie 84, 68-275

Baron-Cohen, S. (1995) Mindblindness: An essay on Autism and the Theory of Mind. Cambridge MA MIT Press

Blurton Jones, N. G. (1972). Ethological Studies of Child Behaviour. London: Cambridge University Press

Blurton Jones, N. G. (1975). Ethology, anthropology and childhood. In R. Fox (Ed.) A.S.A. StudiesBiosocial Anthropology, London. Dent.

Boyd, R. \& Richerson, P. (1996) Why culture is common but cultural evolution is rare. Proceedings of the British Academy. 88, 73-93.

Browne, J. (1995). Charles Darwin: A Biography, Vol. 1 - Voyaging, p 499. Knopf, New York.

Bowlby, J. (1969). Attachment and Loss, Vol. 1. Attachment. Hogarth, London.

Buccino, G., Lui F., Canessa, N., Patteri, I, Lagravinese, G., Benuzzi, F., Porro, C.A. \& Rizzolatte, G. (2004) Neural Circuits Involved in the Recognition of Actions Performed by Nonconspecifics: An fMRI Study. Journal of Cognitive Neuroscience 16:1, 114-126. DOI

Byrne R W, \& Whiten A. (1988) Machiavellian Intelligence: Social Expertise and the Evolution of Intellect in Monkeys, Apes and Humans. Oxford, Oxford University Press

Cassidy, J and Shaver, P.R. (2008) Handbook of Attachment. New York, Guildford Press

Clay, Z., Archbold, J., \& Zuberbühler, K. (2015) Functional flexibility in wild bonobo vocal behaviour. Peer J 3:e1124. DOI

Colle, L., Becchio, C., \& Bara, B.G. (2008) The Non-Problem of the Other Minds: A Neurodevelopmental Perspective on Shared Intentionality. Human Development. 51, 336348. DOI

Cortina M. \& Liotti, G. (2010) Attachment is about safety and protection, intersubjectivity is about sharing and social understanding. The relationships between attachment and intersubjectivity. Psychoanalytic Psychology 27 (4), 410-441. DOI

Crittenden, P.M. (2008) Raising Parents. Cullompton Willan. DOI

Dawkins, R. (1976) The Selfish Gene. Oxford, Oxford University Press.

Dawkins, R \& Krebs, J.R. (1978) Animal signals: information or manipulation? In Behavioural Ecology: an evolutionary approach 1st ed. (Krebs, JR \&, Davies, NB, eds) Blackwell: Oxford, 282-309.

Donne, J. (1923). Donne's Devotions. Cambridge University Press

Dubreuil, B. \& Henshilwood, C. (2013) Archeology and the language-ready brain. Language and Cognition; 5(2-3): $251-260$. DOI

Dunbar, R. (1995). The Trouble with Science. London, Faber \& Faber 
Fonagy, P , Gergely, G., Elliot L. Jurist,E.L. \& Target, M. (2004) Affect Regulation, Mentalization, and the Development of the Self. New York: Other Press,

Fonagy, P, Bateman, A. \& Bateman, A. (2011) The Widening Scope of Mentalization: A discussion. Psychology and Psychology and Psychotherapy: Theory, Research and Practice, 84, 98-110. DOI

Frith, U. (1989) Autism: Explaining the Enigma. Oxford. Basil Blackwell

Frith, U. \& Frith, C.D. (2003) Development and neurophysiology of mentalizing. Philosophical Transactions of the Royal Society of London Biological Sciences, 358, 459-473. DOI

Gallese, V., Keysers, C., \& Rizzolatti, G. (2004). A unifying view of the basis of social cognition. Trends in Cognitive Sciences, 8, 396-403. DOI

Garland, A. (writer and director) (2015) Ex Machina. Film4 + DNA Films. Distributor in UK: Universal Pictures, in USA: A24

Godfrey-Smith, P. (2003) Theory and Reality, Chicago, University of Chicago Press. DOI

Grant, E.C. (1969) Human Facial Expressions. Man 4 525-536. DOI

Haidt, J. (2012) The Righteous Mind. London, Allen Lane

Haig, B. (2009) Methods: Evaluating explanatory theories. The Psychologist, 22, 948-951

Harré, R, and Secord, P. (1972) The Explanation of Social Behaviour. Oxford: Blackwell.

Hinde, R.A. (1953) The term Mimesis. British Journal of Animal Behaviour 1, 7-9. DOI

Henshilwood, C. (2012) Late Pleistocene Techno-traditions in Southern Africa: A Review of the Still Bay and Howiesons Poort, c. 75-59 ka. Journal of World Prehistory 25, 205-237. DOI

Henshilwood, C. \& B. Dubreuil. (2009). Reading the artefacts: Gleaning language skills from the Middle Stone Age in Southern Africa. In R. Botha \& C. Knight (eds.), The cradle of language, 41-60. Oxford: Oxford University Press.

Henshilwood, C. \& B. Dubreuil. (2011). The Still Bay and Howiesons Poort, 77-59 ka: Perspectivetaking and the evolution of the modern human mind during the African Middle Stone Age. Current Anthropology, 52.361-400. DOI

Hobaiter, C., \& Byrne, R W (2014). The meanings of chimpanzee gestures. Current Biology, 24, 14, 1596-1600. DOI

Humphrey, N.K. (1976) The social function of intellect. In: Growing Points in Ethology, (eds). P.P.G. Bateson \& R.A. Hinde, pp. 303- 317, Cambridge, Cambridge University Press,

Humphrey, N.K. (1982) Consciousness: a just-so story. New Scientist. 95, 474-8

Kesebir, S. (2012) The Superorganism Account of Human Sociality: How and When Human Groups are Like Beehives. Personality \& Social Psychology Review. 16 (3) 233-261. DOI

Keynes R (2001) Annie's Box: Charles Darwin, his Daughter, and Human Evolution. Fourth Estate Publishers, London. 
Knight, C. (2000). The evolution of cooperative communication. In Knight, C., M. StuddertKennedy \& J. R. Hurford (eds), The Evolutionary Emergence of Language: Social Function and the Origins of Linguistic Form. Cambridge: Cambridge University Press, pp. 19-26. DOI

Krebs, J. \& Dawkins, R. (1984) Animal signals: mind-reading and manipulation. In Behavioural Ecology: an evolutionary approach, 2nd ed (Krebs, J.R. \&, Davies, N.B., eds), Sinauer: 380402.

Lehrman, D.S. (1970) Semantic and conceptual issues in the nature-nurture problem. In L. Aronsen, E. Tobach, D.S,Lehrman and J.S. Rosenblatt (eds) Development and evolution of behavior (pp 17-52) New York, W.H.Freeman.

Lumsden, C. J. \& Wilson, E. O. (1980). Translation of epigenetic rules of individual behaviour into ethnographic patterns. Proceedings of the National Academy of Sciences of the USA, 774382. DOI

Lyman RL \& O'Brien MJ (2003) Cultural traits: Units of analysis in early twentieth century anthropology. Journal of Anthropological Research, 59, 225-250. DOI

MacKay, D.M. (1960) On the logical indeterminacy of a free choice. Mind, 69, 31-40. DOI

McGrew, W.C. (1970) Glossary of motor patterns of four-year-old children. In: Direct Observation and Measurement of Behavior. Hutt, S.J. \& C. (Eds), Springfield, IL: Charles C. Thomas, pp. 210-218.

McGrew, W. C. (2005) The cultured chimpanzee: reflections on cultural primatology. Cambridge, UK: Cambridge University Press. DOI

Mayr, Ernst (1997). The objects of selection. Proceedings of the National Academy of Sciences of the United States of America (Stanford University's HighWire Press ${ }^{\circledR}$ ) 94 (6): 2091-2094. DOI

Massie, H.N. (1978a) Blind ratings of mother-infant interaction in home movies of prepsychotic and normal infants. American Journal of Psychiatry. 135(11), 1371-74. DOI

Massie, H.N. (1978b) The early natural history of childhood psychosis. Ten cases studied by analysis of family home movies of the infancies of the children. Journal of the American Academy of Child Psychiatry. 17(1), 29-45. DOI

Mead, C. (1990) Neuromorphic Electronic Systems, Proceedings of the IEEE, 78 (10), 1629- 1639. DOI

Medawar, P.B. (1967) Science, the Art of the Soluble. Methuen, London

Meltzoff, A.N. \& Moore, M.K. (1977) Imitation of facial and manual gestures by human neonates. Science 198, 75-78. DOI

Murray, L. (1980). The sensitivities and expressive capacities of young infants in communication with their mothers. Unpublished Ph.D. thesis, University of Edinburgh.

Murray, L. \& Trevarthen, C. (1986) The infant's role in mother-infant communication. Journal of Child Language 13, 15-29. DOI 
Murray, L. \& Trevarthen, C. B. (1985). Emotional regulation of interactions between 2 month olds and their mothers. In Field, T. M. \& Fox N. A. (eds), Social perception in infants. New Jersey: Ablex.

Nagel, J. (2014) Knowledge: A Very Short Introduction. Oxford. Oxford University Press. DOI

Newson, J., \& Newson, E. (1975). Intersubjectivity and the transmission of culture; on the social origins of symbolic functioning. Bulletin of the British Psychological Society, 28, 437-446

Noble. J. (2000) Cooperation, competition, and the evolution of pre linguistic communication. In: The Evolutionary Emergence of Language: Sociasl function and the origins of linguistic form. (eds) Knight, C., Studdert-Kennedy, M., Hurford, J.R. Cambridge: Cambridge University Press. pp 40-61. DOI

Pike, K.L. (1967). Language in Relation to a Unified Theory of the Structure of Human Behaviour. Mouton, Elmsford, New York: Glendale Summer Institute of Linguistics. DOI

Ray, E and Heyes C (2011) Imitation in infancy: the wealth of the stimulus. Developmental Science 14 , Issue $1,92-105$. DOI

Richer, J.M. (1974). Direct Observation - a reply to Cooper et al. Bulletin of the British Psychological Society, 27, 500-502.

Richer, J.M. (1975) Two types of agreement - two types of psychology. Bulletin of the British Psychological Society, 28. 342-345. (Reprinted in Readings in psychology for the Teacher. Child D. (ed) Holt, Rinehart, \& Winston, London 1977)

Richer, J.M. (1976) Social avoidance in autistic children. Animal Behaviour, 24, 898-906. DOI

Richer, J.M. (1979) Human ethology and mental handicap. In: James, F.C. and Snaith, R.P. (eds) Psychiatric Illness and Mental Handicap London: Gaskell.

Richer, J.M. (1978) The partial non communication of culture to autistic children. In Rutter, M. and Schopler, E. (eds) Autism: reappraisal of concepts and treatment. Plenum Press. New York. DOI

Richer, J.M. (2001a) An Ethological Approach to Autism: From Evolutionary Perspectives to Treatment. In: Richer, J.M. and Coates, S. (eds) (2001) Autism: The Search for Coherence. London: Jessica Kingsley.

Richer, J.M. (2001b) The Insufficient Integration of Self and Other in Autism. In Richer, J.M. and Coates, S. (eds) Autism: The Search for Coherence. London; Jessica Kingsley.

Richer, J.M. (2014a) "Disordered" behaviour. Alternatives to DSM-5 from and ethological perspective. Human Ethology Bulletin, 29(2), 27-55.

Richer, J.M. (2014b) Ethology and "Mental Illness". In P. LaFreniere and G Weisfeld (Eds) Evolutionary Science of Human Behavior: An Interdisciplinary Approach.

Richerson, PJ \& Boyd, R T (1999) Complex societies - The evolutionary origins of a crude superorganism. Human Nature, 10(3), pp.253-289. DOI 
Richerson, PJ, Boyd, R.T \& Henrich, J (2003) Cultural Evolution and human Cooperation. In: Genetic and Cultural Evolution of Cooperation, Hammerstein P (ed) Cambridge. Massachusetts Institute of Technology Press

Spencer, H. 1891. Essays: Scientific, political, and speculative. 3 volumes. London: Williams and Norgate.

Tinbergen (1951) The Study of Instinct. Oxford. Oxford University Press.

Tinbergen, N. (1963) On the aims and methods of ethology. Zeitschrift fur Tierpsychologie, 20, 41033. DOI

Tomasello, M., Kruger, A.C. \& Ratner H.H. (1993) Cultural learning. Behavior and Brain Science, 16, 495-552. DOI

Trevarthen, C. (1977) Descriptive analyses of infant communicative behaviour. In H.R. Schaffer (Ed) Studies in Mother-Infant Interaction. London, Academic Press.

Trevarthen, C. (1980). The foundations of intersubjectivity: development of interpersonal and cooperative understanding in infants. In D. Olson (Ed) The Social Foundations of Language and Thought: Essays in Honour of J.S. Bruner. New York, Norton.

Trevarthen C, Aitken KJ. (2001) Infant intersubjectivity: research, theory, and clinical applications. Journal of Child Psychology and Psychiatry. 42(1), 3-48. DOI

Trevarthen, C. \& Aitken, K. (2003) Regulation of Brain Development and Age-Related Changes in Infants' Motives: The Developmental Function of Regressive Periods. In. Heiman M (Ed) Regression Periods in Human Infancy. Mahwah NJ. Lawrence Erlbaum Associates.

Tuma, T, Pantazi, A., Sebastian, \& A.,Eleftheriou, E. (2016). Stochastic phase-change neurons. Nature Nanotechnology, 11, 693-699. DOI

Watson, J.B. (1913). Psychology as the Behaviorist Views it. Psychological Review, 20, 158-177. DOI

Whiten A., \& Byrne R W. (1997). Machiavellian Intelligence II. Extensions and Evaluations. Cambridge. Cambridge Univ. Press. DOI

Whiten, A. \& van Schaik C.P. (2007). The evolution of animal "cultures" and social intelligence. Philosophical Transactions of the Royal Society B 29, Vol 362 (number 1480), 603-620. DOI

Williams, D. (1996). Autism: an Inside-Out Approach. Doubleday, London.

Wilson, E. O. (2012). The Social Conquest of Earth. New York, Liveright

Wittgenstein, L. (1953). Philosophical Investigations. Oxford, Blackwell. 